\title{
The Role of the Disintegrin Metalloproteinase ADAM15 in Prostate Cancer Progression
}

\author{
Neali Lucas and Mark L. Day* \\ Department of Urology, University of Michigan, Ann Arbor, Michigan
}

\begin{abstract}
The metalloproteinase ADAM15 is a multi-domain disintegrin protease that is upregulated in a variety of human cancers. ADAM15 mRNA and protein levels are increased in prostate cancer and its expression is significantly increased during metastatic progression. It is likely that ADAM15 supports disease progression differentially through the action of its various functional domains. ADAM15 may downregulate adhesion of tumor cells to the extracellular matrix, reduce cell-cell adhesion, and promote metastasis through the activity of its disintegrin and metalloproteinase domains. Additionally, ADAM15 can influence cell signaling by shedding membrane-bound growth factors and other proteins that interact with receptor tyrosine kinases, leading to receptor activation. There is also evidence supporting a role for ADAM15 in angiogenesis and angioinvasion of tumor cells, which are critical for unrestrained tumor growth and metastatic spread. Given its diverse functions, ADAM15 may represent a pivotal regulatory component of tumor progression, an important target for therapeutic intervention, or emerge as a biomarker of disease progression. J. Cell. Biochem. 106: 967-974, 2009. ( 2009 Wiley-Liss, Inc.
\end{abstract}

\section{KEY WORDS: PROSTATE CANCER; PROTEASE; DISINTEGRIN; METALLOPROTEINASE}

$\mathrm{T}$ he ADAM (A Distintegrin And Metalloproteinase) family of proteins consists of 21 type I, multi-domain glycoproteins, 13 of which have proteolytic activity [Edwards et al., 2008]. These disintegrin proteases have several characteristic protein domains including the: prodomain, metalloproteinase, disintegrin, cysteinerich, EGF-like, transmembrane, and cytoplasmic domains [Edwards et al., 2008]. The various domains of ADAM proteins have different proposed functions. Removal of the prodomain, presumably by proprotein convertases, is a critical step in the catalytic activation of the metalloproteinase domain. The disintegrin domain, named for its homology to peptides found in snake venom metalloproteinases, is hypothesized to abrogate integrin binding to adjacent cells, and modification of cell-cell or cell-extracellular matrix interactions can facilitate cancer cell metastasis. The cysteine-rich domain is thought to regulate cell fusion and may also be involved in the activation of latent ADAMs and removal of the prodomain through mechanisms that are not fully elucidated [Wolfsberg et al., 1995; Loechel et al., 1998]. The EGF-like domain is one of the characteristic protein domains contained by ADAM family members. This domain is named for its similarity to epidermal growth factor (EGF) and other related growth factors containing six, highly conserved cysteine residues with characteristic spacing [Wolfsberg et al., 1993]. Although some data suggests the EGF-like domain may be involved in substrate specificity, by and large, a paucity of data exists regarding the role of this domain in substrate cleavage and recognition [Smith et al., 2002].

The various domains of ADAMs suggests that these multifunctional proteins may have divergent consequences on cellular processes. In fact, these proteins have been implicated in a wide array of cellular functions such as sperm-egg fusion, ectodomain shedding, and cell adhesion [For a comprehensive review of ADAM proteins see Edwards et al., 2008]. Because ADAMs play significant roles in the regulation of normal cell physiology, deregulation of ADAM expression or activity may result in pathologic states, including cancer.

\section{ADAMs IN CANCER}

Several members of the ADAM family have been implicated in tumorigenesis of various organs [for a comprehensive review see Murphy, 2008]. Prostate cancer is the second leading cause of cancer death of men in the United States; approximately 29,000 men will die this year of the disease [ACS, 2008]. Although men have a 1 in 6 lifetime risk of developing prostate cancer, only 1 man in 35 will die of this disease. Mortality from prostate cancer as with many other cancers, is largely due to metastatic disease progression. Additionally, treatments for advanced, metastatic prostate cancer
*Correspondence to: Mark L. Day, Department of Urology, University of Michigan, 6219 CCGC, 1500 E. Medical Center Drive, Ann Arbor, MI 48109-5944. E-mail: mday@umich.edu

Received 7 January 2009; Accepted 8 January 2009 • DOI 10.1002/jcb.22087 • 2009 Wiley-Liss, Inc.

Published online 19 February 2009 in Wiley InterScience (www.interscience.wiley.com). 
are limited and frequently have an adverse impact on the patients' quality of life. As such, a greater understanding of the mechanisms of prostate cancer progression can facilitate the development of well-tolerated and effective treatments for men with prostate cancer.

Several ADAM family members are implicated in the development and/or progression of prostate cancer. In primary prostate cancer tissue, localization of ADAM10 shifted from the membrane to the nucleus in malignant prostate glands [Arima et al., 2007]. In addition, the expression of ADAM9 increased in prostate cancer and its expression was determined to be an independent marker of disease relapse [Fritzsche et al., 2008]. Furthermore, loss of Adam9 led to increased differentiation of prostate tumors in mice, supporting a role for ADAM9 in the malignant progression of prostate cancer [Peduto et al., 2005]. mRNA and/or protein levels of ADAM15 (MDC15, metargidin) are upregulated in multiple adenocarcinomas including cancer of the breast, stomach, lung, pancreas and prostate [Murphy, 2008]. Additionally, the chromosomal region containing ADAM15 (1q21.3) is known to be amplified in several of these diseases [Alers et al., 2000; Karkkainen et al., 2000; Balazs et al., 2001; El Gedaily et al., 2001; Glinsky et al., 2003]. We reported ADAM15 cDNA and protein levels are significantly increased in prostate tumor tissue and that ADAM15 expression correlates with metastatic disease progression [Kuefer et al., 2006]. A survey of the Oncomine ${ }^{\mathrm{TM}}$ gene expression array database reveals statistically significant overexpression of ADAM15 cDNA in prostate tumor tissue in several other published studies (Table I). Elevated expression of ADAM15 correlates with progression of hormone-refractory, metastatic prostate cancer, and in localized prostate cancer, is strongly associated with high grade disease, as assessed by Gleason sum, or a poor disease outcome [Kuefer et al., 2006]. Together, these results suggest that ADAM15 may play an important role in malignant progression of prostate tumors. As such, a greater understanding of the contributions of ADAM15 to cancer progression will yield insights into mechanisms of tumor progression and may elucidate mechanisms that are amenable to pharmaceutical intervention. Furthermore, considering the findings implicating several ADAM family members in the development or progression of prostate cancer adds another layer of complexity to the potential role of ADAMs in prostate cancer. Closely related family members may interact independently, redundantly, or in a hierarchical manner. Further investigation is required to determine whether ADAMs function independently or synergistically to promote prostate cancer progression. The remainder of this review will focus on ADAM15 and the various means by which ADAM15 can promote metastatic progression of prostate cancer.

\section{CONTRIBUTION OF ADAM15 TO PROSTATE CANCER PROGRESSION}

ADAM15 is a catalytically active disintegrin metalloproteinase. It is postulated that the proteolytic cleavage of ADAM15 substrates can promote prostate cancer progression in various ways including: (1) disruption of cellular attachments to neighboring cells (2) shedding membrane-bound growth factors in an autocrine or paracrine fashion, and (3) by disrupting cellular interactions with the extracellular matrix and basement membrane.

\section{CELL-EXTRACELLULAR MATRIX INTERACTIONS}

Previous work has demonstrated that ADAM15 can proteolytically process several different molecules involved in cell adhesion which can lead to differential effects on cancer cell metastasis. We and others have reported an inverse correlation between ADAM15 expression and the cell surface expression of the adhesion molecules CD44 [Najy et al., 2008a] and integrin $\alpha_{\mathrm{v}}$. CD44 is a cell-surface glycoprotein involved in cell-cell interactions, cell adhesion, and migration through its ability to facilitate interaction with extracellular matrix proteins. $\alpha_{\mathrm{v}}$ integrin, which mediates binding to the extracellular matrix protein vitronectin, was reduced in prostate cancer cells expressing ADAM15. ADAM15 expression also correlated with elevated matrix metalloproteinase activity which can lead to digestion of extracellular matrix components. Together, these findings support a role for ADAM15 in reducing interactions of tumor cells with the extracellular matrix and promoting metastatic progression of prostate cancer.

Although ADAM family members contain a disintegrin domain, ADAM15 is the only member that contains a prototypical RGD motif which is associated with integrin binding. In fact, ADAM15 was reported to bind to various integrins, including $\alpha_{\mathrm{v}} \beta_{3}, \alpha_{\mathrm{v}} \beta_{1}, \alpha_{9} \beta_{1}$ [Zhang et al., 1998; Nath et al., 1999; Eto et al., 2000]. Interaction of the ADAM15 disintegrin domain with integrins can alter cell adhesion. In support of this hypothesis, treatment of endothelial cells with recombinant RGD domain of ADAM15 inhibited cell migration and metastasis of melanoma cells [Trochon-Joseph et al.,

TABLE I. ADAM15 Is Upregulated in Prostate Cancer

\begin{tabular}{llc}
\hline First author & \multicolumn{1}{c}{ Comparison groups } & $P$-value \\
\hline (1) Dhanasekaran & Normal prostate vs. cancer & $5.6 \mathrm{E}-5$ \\
(2) Dhanasekeran & Normal prostate/BPH/cancer vs. metastatic cancer & $1.4 \mathrm{E}-5$ \\
(3) Lapointe & Normal prostate/prostate cancer vs. metastatic cancer & 0.004 \\
(4) Luo & BPH vs. prostate cancer & 0.012 \\
(5) Magee & Normal prostate vs. prostate cancer \\
(6) Tomlins & Normal prostate vs. prostate cancer \\
(7) Vanaja & Normal prostate vs. prostate cancer \\
(8) Varambally & Normal prostate vs. prostate cancer & 0.023 \\
(9) Yu & Normal prostate/prostate cancer vs. metastatic cancer & 0.014 \\
\hline
\end{tabular}

The above table summarizes cDNA microarray studies from the Oncomine ${ }^{\mathrm{TM}}$ database (www.oncomine.org) that report upregulation of ADAM15 mRNA levels in prostate cancer. BPH, benign prostatic hyperplasia. (1) Dhanasekaran et al. [2001], (2) Dhanasekaran et al. [2005], (3) Lapointe et al. [2004], (4) Luo et al. [2001], (5) Magee et al. [2001], (6) Tomlins et al. [2007], (7) Vanaja et al. [2003], (8) Varambally et al. [2005], (9) Yu et al. [2004]. 
2004]. ADAM15 is also upregulated in osteoarthritis and other inflammatory diseases [Reviewed by Charrier-Hisamuddin et al., 2008] and it is believed to enhance integrin-mediated adhesion of chondrocytes to the collagen matrix [Bohm et al., in press]. In addition, overexpression of ADAM15 in Chinese hamster ovary (CHO) cells promotes adhesion to fibronectin but decreases cell invasion and motility through modified cell signaling and increased cell surface localization of $\alpha_{5} \beta_{1}$ integrin. It is clear that ADAM15 is capable of interacting with integrins through its disintegrin domain, however a great deal of work lies ahead to fully understand the implications of these interactions in cell adhesion, migration, integrin-related signaling, and metastasis.

\section{CELL-CELL ADHESION}

In addition to modifying cell-extracellular matrix interactions, ADAM15 can modulate cell-cell adhesion by proteolytic cleavage of cadherin cell adhesion molecules. PC-3 cells represent a highly malignant prostate cancer cell line that has high tumorigenicity and metastatic potential in nude mice. Consistent with this phenotype, PC-3 cells exhibit low-level expression of the metastasis suppressor and epithelial cell marker E-cadherin, and high levels of neuronal cadherin, $\mathrm{N}$-cadherin. $\mathrm{N}$-cadherin mediates heterotypic interaction of tumor cells with the microenviroment and has been reported to promote motility and invasion of tumor cells [Nieman et al., 1999; Najy et al., 2008a]. We demonstrated that, in PC-3 cells, ADAM15 mediates the cleavage and release of $\mathrm{N}$-cadherin, which may promote migration of tumor cells. Further supporting this argument was our finding that reduced ADAM15 expression in PC-3 cells inhibited binding to and transmigration through vascular endothelial cells. This finding suggests that ADAM15 promotes intravasation of prostate cancer cells into the circulation by reducing cell adhesion and facilitating tumor-endothelial cell interactions.

In secretory tissues, such as the prostate gland, inter-epithelial membrane adhesion is dependent on the homophilic interaction of the cell adhesion protein E-cadherin at adherens junctions. The function of E-cadherin in cell adhesion is dependent on its ability to interact with the catenin proteins, $\alpha$-catenin, $\beta$-catenin and $\delta$-catenin/plakoglobin through its cytoplasmic domain [Nagafuchi and Takeichi, 1989; McCrea and Gumbiner, 1991; Miller and Moon, 1997]. The role of E-cadherin gene mutation and promoter hypermethylation in malignant transformation and tumor progression has been studied thoroughly [Hajra et al., 1999; Murant et al., 2000]. One regulatory mechanism of E-cadherin expression that has received little examination is the proteolytic processing of E-cadherin in human disease.

The first reports of E-cadherin proteolysis emerged with the discovery of an extracellular, $80 \mathrm{kDa}$ fragment referred to as soluble E-cadherin, sE-cad, which was shed into the media of mouse and human mammary tumor cells following serum deprivation [Wheelock et al., 1987]. Following this discovery, sE-cad was shown to be elevated in the serum of patients suffering from gastric, hepatocellular, lung, and breast cancers [Gofuku et al., 1998]. We have also demonstrated that the levels of sE-cad are significantly elevated in the serum of patients suffering from metastatic prostate cancer [Kuefer et al., 2003]. Given that both levels of sE-cad and ADAM15 expression increase during the metastatic progression of prostate cancer, we sought to determine whether ADAM15 can cleave E-cadherin. We found that ADAM15 cleaves E-cadherin to generate sE-cad in breast and prostate cancer cells (data not shown) [Najy et al., 2008b]. These findings may represent a novel mechanism by which tumor cells downregulate E-cadherin, disrupt cell-cell adhesion, and promote cancer cell metastasis.

In addition to modifying cell adhesion by disrupting adherens junctions, ADAM15 has been recently implicated in ectodomain shedding of the desmosomal protein, DSG2 [Klessner et al., 2009]. DSG2 is a transmembrane protein that contributes to cell adhesion by homophilic binding of the extracellular domains on adjacent cells. DSG2 tethers to the cytoskeleton through interactions of the intracellular domain, similar to E-cadherin. ADAM15-dependent disruption of cell adhesion by cleavage of DSG2 may be relevant in prostate cancer metastasis. DSG2 is expressed in prostate cells [Schafer et al., 1994] and loss of desmosomal components has been previously implicated in prostate cancer pathogenesis [Shiina et al., 2005]. The consistent upregulation of ADAM15 in a variety of adenocarcinomas and the overlapping mechanisms by which ADAM15 interferes with the interaction of tumor cells with each other and the extracellular matrix supports the notion that upregulation of ADAM15 in prostate cancer cells promotes cell detachment, basement membrane degradation, and subsequent invasion and metastasis. This pro-metastatic phenotype associated with ADAM15 may be relevant to other tumor types.

\section{CELL SIGNALING}

In addition to modulating cell adhesion, the proteolytic activity of ADAM family members may play critical roles in ectodomain shedding of membrane-bound growth factors leading to the activation of receptor tyrosine kinases. The high affinity epidermal growth factor receptor (EGFR) ligands heparin-binding EGF-like growth factor (HB-EGF) and amphiregulin (AR) were identified as ADAM15 substrates in breast and kidney cancer cells, respectively [Schafer et al., 2004; Hart et al., 2005]. ADAM15 was also implicated in stimulation of G-protein coupled receptor (GPCR)-mediated of EGFRs. GPCR stimulation initiates ADAM-dependent shedding of EGFR ligands, such as AR, in multiple systems although the mechanisms are not well-defined [Reviewed by Ohtsu et al., 2006]. For example, ADAM family members differentially facilitate EGFR transactivation in response to GPCR agonists in bladder cancer cells. ADAM17 promoted Angiotensin II-stimulated EGFR transactivation whereas lysophosphatidic acid (LPA)-induced transactivation was shown to be ADAM15-dependent in bladder cancer cells [Schafer et al., 2004].

As discussed above, ADAM15 catalytic activity can lead to EGFR transactivation by liberating membrane-bound ligands. In addition, receptor tyrosine kinases can be activated by interaction with cadherin proteins [Schafer et al., 1994; Suyama et al., 2002; Boscher and Mege, 2008]. Specifically, the interaction of N-cadherin with FGFR was linked to metastasis of breast cancer cells, supporting the hypothesis that these interactions may play a role in cancer progression [Suyama et al., 2002]. There is now considerable evidence to support that EGFR transactivation can also occur by interaction of soluble cadherins processed by ADAMs with EGFRs. We have recently demonstrated the provocative finding that 
ADAM15 can cleave E-cadherin to produce an $80 \mathrm{kDa}$ form (sE-cad) which can bind to and activate HER2/neu/ErbB-2 in breast cancer cells [Najy et al., 2008b]. In breast cancer cells, ADAM15 expression resulted in increased ERK signaling and cell migration. A likely consequence of ADAM15 modulating cell signaling is modified gene transcription. As such, we demonstrated that ADAM15 promotes transcription of several known proteases and protease inhibitors. Of particular interest, was the downregulation of caspase- 3 by ADAM15, suggesting a potential mechanism through which ADAM15 may increase cell survival [Kuefer et al., 2006].

Activation of HER2 by ADAM15 could also be significant in prostate cancer development and progression. For example, HER2 has been implicated in several reports to drive progression of prostate cancer cells to androgen independent, hormone refractory disease [Craft et al., 1999; Shi et al., 2004; Berger et al., 2006]. HER2 expression was reported to be increased in patients given hormone ablation therapy and in those with androgen independent tumors [Signoretti et al., 2000; Shi et al., 2001; Berger et al., 2006]. Also, soluble HER2 was elevated in the serum of men with advanced prostate cancer and elevated protein levels were associated with poor clinical outcome as measured by PSA progression. Given, the potential role of HER2 in driving prostate cancer progression, activation of HER2 by sE-cad binding represents a novel axis whereby ADAM15 can promote progression and survival of prostate and breast cancer cells and contribute to malignant disease progression (Fig. 1).

In breast cancer cells, ADAM15 expression resulted in increased ERK signaling and cell migration [Najy et al., 2008b]. A likely consequence of ADAM15 modulating cell signaling is modified gene transcription. As such, we demonstrated that ADAM15 promotes transcription of several known proteases and their respective inhibitors in a manner consistent with increased cell survival [Kuefer et al., 2006]. In addition to the effects of the catalytic domain on cell signaling, little is known concerning whether the other domains, such as the EGF-like domain, also contribute to ADAM15mediated effects on cell signaling.

\section{THE ROLE OF ADAM15 IN ANGIOGENESIS}

Without the ability to generate a blood supply through the process of angiogenesis, the growth of a tumor is restricted to approximately $1 \mathrm{mM}$ in size [Folkman, 1990] at which point it is likely to be clinically insignificant. High levels of ADAM15 expression in the endothelium suggests it may play a role in endothelial function or pathology such as promoting blood vessel formation in tumors.

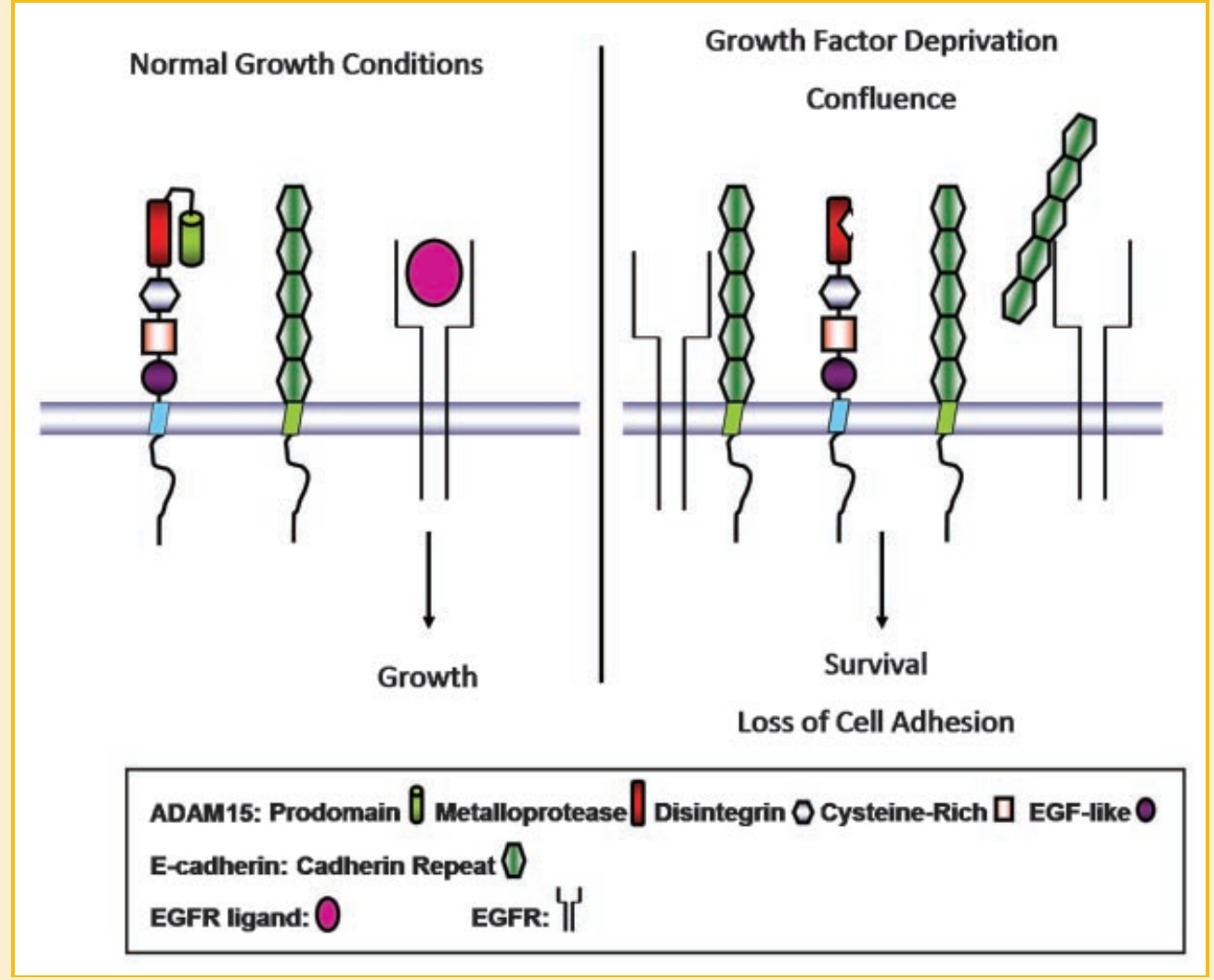

Fig. 1. Model of the effects of ADAM15 catalytic activity on cell signaling. In addition to shedding membrane-bound growth factors, ADAM15 can cleave the cell adhesion molecule E-cadherin to generate a soluble form (sE-cad). Cleavage of E-cadherin by ADAM15 can promote cancer cell metastasis in several ways. Downregulation of E-cadherin by proteolytic cleavage can promote loss of cell adhesion and binding of $s E-c a d$ to growth factor receptors promotes cancer cell signaling. In addition, activation of ADAM15 is increased at both high cell density and in response to growth factor withdrawal which would allow cancer cells to overcome anti-growth signals and to survive at distant sites, respectively. 
Although ADAM15 does not appear to be required for developmental angiogenesis, Adam $15^{-/-}$mice have a reduced capacity to form new blood vessels under pathological conditions. Specifically, Adam15-null mice exhibited less angiogenesis in a model of retinopathy and the growth of melanoma cells was reduced in these mice compared to wild type controls [Horiuchi et al., 2003]. In addition, ADAM15 colocalizes with vascular endothelial cadherin (VE-cadherin) in the adherens junctions of endothelial cells and expression of VE-cadherin can drive cell surface expression of ADAM15, suggesting some functional interaction of these proteins in endothelial cells [Ham et al., 2002]. Little is known regarding the mechanisms of ADAM15 involvement in angiogenesis, but the ability of this protein to proteolytically digest the extracellular matrix components gelatin and type IV collagen, which are required for endothelial cell migration and sprouting, further suggests that ADAM15 may promote angiogenesis [Martin et al., 2002]. Furthermore, ADAM15 can upregulate the expression and activity of the pro-angiogenic factor MMP9 [Bergers et al., 2000; Najy et al., 2008a]. The activity of MMP9 is related to increased invasiveness of prostate cancer [Zhang et al., 2004]. Therefore, in addition to the direct contributions of ADAM15 to angiogenesis, upregulation of pro-angiogenic genes may further promote a malignant phenotype.

The interaction of ADAM15 with integrins through its disintegrin domain may also facilitate angiogenesis. As mentioned previously, ADAM15 interacts with $\alpha_{\mathrm{v}} \beta 3$ and $\alpha_{5} \beta_{1}$ integrins, both of which are involved in endothelial cell migration [Eliceiri and Cheresh, 2000; Kim et al., 2000; Moiseeva, 2001]. As such, the recombinant human ADAM15 disintegrin domain (RDD) inhibited endothelial cell growth, migration and angiogenesis. RDD also inhibited growth and angiogenesis of breast cancer cells and metastasis of melanoma cells in vivo. Together, these data suggest that ADAM15 plays a role in several processes associated with the angiogenic potential of tumors.

\section{SUMMARY}

A great deal has been elucidated concerning the functions of ADAM15 since its identification and cloning [Kratzschmar et al., 1996]. mRNA and protein levels of ADAM15 are upregulated in cancer of various organs. In several independent studies overexpression of ADAM15 in metastatic prostate cancer has been reported, supporting the notion that ADAM15 plays an important role in tumor development and/or progression. As ADAM15 contains multiple functional domains, this disintegrin metalloproteinase likely regulates tumor progression through diverse mechanisms. In fact, considering the required characteristics for cellular transformation discussed by Hanahan and Weinberg [2000], ADAM15 contributes to many of the processes described. Through shedding of membrane bound growth factors and cleavage of cadherin molecules that can activate cell signaling, ADAM15 can promote self-sufficiency in growth signals of prostate cancer cells. As E-cadherin contributes to cell-cell adhesion and contact inhibition of cells, cleavage of this molecule for use as a growth factor can allow cancer cells to overcome intrinsic growth inhibition mechanisms. Similarly, use of cadherins as signaling molecules can enhance cell survival and evasion of apoptosis, promoting survival of metastatic cancer cells at distant sites. It is also compelling that ADAM15 activity is increased at both high cell density and in response to growth factor withdrawal in prostate cancer cells (Mark L. Day, unpublished data) which further suggests roles for ADAM15 in overcoming anti-growth signals and promoting survival at distant sites, respectively.

The pro-metastatic capability of ADAM15 in prostate tumor progression was demonstrated in SCID mice [Najy et al., 2008a]. The increased gene expression and protein levels of ADAM15 in metastatic prostate cancer is also compelling evidence that supports its role in tissue invasion and metastasis. Although the mechanisms are not completely clear, the cleavage of cell adhesion molecules, interactions of the disintegrin domain, and effects on cell migration are likely players. Lastly, it seems as though ADAM15 may play an important role in stimulating angiogenesis. Together, these findings support the notion that ADAM15 plays a critical role in prostate cancer progression and is a viable therapeutic target for prostate cancer.

Although significant inroads in understanding the impact of ADAM15 on cell biology have been made, a great deal more remains to be discovered. Very little is known about the requirements of substrate specificity for ADAMs. Some data has implicated the cysteine-rich domain and, possibly, the EGF-like domain in substrate specificity however, the requirements for ADAM15 substrate specificity remain largely unknown. Although little is known concerning the role of the EGF-like domain in ADAM function, it is tempting to speculate whether this domain plays a role in ADAM15-dependent effects on cell signaling given the reported role of ADAM15 in EGFR-dependent signaling.

In comparison to other ADAM family members, very little is known regarding the catalytic substrates of ADAM15. Identification of these proteins may yield important insights into tumor progression and may serve as useful indicators of disease progression. With the advent of PSA screening we have seen great advances in the detection of prostate cancer, the challenge we now face is to identify appropriate treatment for men diagnosed with this disease that consider comorbity, age, etc in meaningful way. As mentioned previously, only a fraction of the men diagnosed with prostate cancer will succumb to the disease [ACS, 2008]. The challenge now for researchers and clinicians is to identify which men have aggressive forms of cancer so that patients are not subjected to the side effects and expense of unnecessary treatment. In addition, we must better understand mechanisms of progression so that effective and targeted treatments can be developed. Furthermore, identifying easily assayed markers of drug efficacy to inform treatment decisions is an important point of investigation. As such, soluble ADAM15 substrates may serve as useful indicators of drug efficacy.

Given the various roles of ADAM15 in cancer progression it may be a desirable target for pharmaceutical intervention. Inhibitors of the catalytic activity of other ADAMs, namely ADAM10 and -17, have been developed and are currently in clinical trials for treatment of breast cancer. These drugs were developed due to the role of these ADAMs in the activation of EGFRs by shedding membrane-bound 
growth factors. EGFRs are of particular interest in prostate cancer in that these tyrosine kinase receptors are reported to be overexpressed in approximately 40\% of prostate tumors [Visakorpi et al., 1992; Di Lorenzo et al., 2002]. Also, inhibition of EGFRs with a small molecule inhibitor increased sensitivity of prostate cancer cells to ionizing radiation [Liu et al., in press]. The development of ADAM15 inhibitors should have minimal side effects for patients since ADAM15 is not thought to be essential for the function of adult cells. Compared to Adam 10 and -17 knockout mice, which exhibit embryonic and perinatal lethality respectively, Adam 15-null mice are viable and fertile [Zhao et al., 2001; Hartmann et al., 2002; Horiuchi et al., 2003]. In addition, ADAMs may be useful as an adjunct therapy to increase the effectiveness of currently used drugs. The recent report that the use of EGFR and ADAM inhibitors in combination resulted in synergistic growth inhibition of human breast cancer cells in vivo [Witters et al., 2008] supports this notion. Although much work remains to understand the mechanisms of ADAM15 in cancer progression, a great deal of data exists supporting a role for the disintegrin protease as a pivotal regulator of prostate cancer cell metastasis.

\section{ACKNOWLEDGMENTS}

This work was supported by the Department of Defense (W81XWH07-1-0030).

\section{REFERENCES}

ACS. 2008. Cancer Facts \& Figures 2008. American Cancer Society.

Alers JC, Rochat J, Krijtenburg PJ, Hop WC, Kranse R, Rosenberg C, Tanke HJ, Schroder FH, van Dekken H. 2000. Identification of genetic markers for prostatic cancer progression. Lab Invest 80:931-942.

Arima T, Enokida H, Kubo H, Kagara I, Matsuda R, Toki K, Nishimura H, Chiyomaru T, Tatarano S, Idesako T, Nishiyama K, Nakagawa M. 2007. Nuclear translocation of ADAM-10 contributes to the pathogenesis and progression of human prostate cancer. Cancer Sci 98:1720-1726.

Balazs M, Adam Z, Treszl A, Begany A, Hunyadi J, Adany R. 2001. Chromosomal imbalances in primary and metastatic melanomas revealed by comparative genomic hybridization. Cytometry 46:222-232.

Berger R, Lin DI, Nieto M, Sicinska E, Garraway LA, Adams H, Signoretti S, Hahn WC, Loda M. 2006. Androgen-dependent regulation of Her-2/neu in prostate cancer cells. Cancer Res 66:5723-5728.

Bergers G, Brekken R, McMahon G, Vu TH, Itoh T, Tamaki K, Tanzawa K, Thorpe P, Itohara S, Werb Z, Hanahan D. 2000. Matrix metalloproteinase-9 triggers the angiogenic switch during carcinogenesis. Nat Cell Biol 2:737744.

Bohm BB, Schirner A, Burkhardt H. in press. Adam 15 modulates outside-in signaling in chondrocyte-matrix interactions. J Cell Mol Med.

Boscher C, Mege RM. 2008. Cadherin-11 interacts with the FGF receptor and induces neurite outgrowth through associated downstream signalling. Cell Signal 20:1061-1072.

Charrier-Hisamuddin L, Laboisse CL, Merlin D. 2008. ADAM-15: A metalloprotease that mediates inflammation. FASEB J 22:641-653.

Craft N, Shostak Y, Carey M, Sawyers CL. 1999. A mechanism for hormoneindependent prostate cancer through modulation of androgen receptor signaling by the HER-2/neu tyrosine kinase. Nat Med 5:280-285.
Dhanasekaran SM, Barrette TR, Ghosh D, Shah R, Varambally S, Kurachi K, Pienta KJ, Rubin MA, Chinnaiyan AM. 2001. Delineation of prognostic biomarkers in prostate cancer. Nature 412:822-826.

Dhanasekaran SM, Dash A, Yu J, Maine IP, Laxman B, Tomlins SA, Creighton CJ, Menon A, Rubin MA, Chinnaiyan AM. 2005. Molecular profiling of human prostate tissues: Insights into gene expression patterns of prostate development during puberty. FASEB J 19:243-245.

Di Lorenzo G, Tortora G, D’Armiento FP, De Rosa G, Staibano S, Autorino R, D'Armiento M, De Laurentiis M, De Placido S, Catalano G, Bianco AR, Ciardiello F. 2002. Expression of epidermal growth factor receptor correlates with disease relapse and progression to androgen-independence in human prostate cancer. Clin Cancer Res 8:3438-3444.

Edwards DR, Handsley MM, Pennington CJ. 2008. The ADAM metalloproteinases. Mol Aspects Med 29:258-289.

El Gedaily A, Bubendorf L, Willi N, Fu W, Richter J, Moch H, Mihatsch MJ, Sauter G, Gasser TC. 2001. Discovery of new DNA amplification loci in prostate cancer by comparative genomic hybridization. Prostate 46:184-190.

Eliceiri BP, Cheresh DA. 2000. Role of alpha v integrins during angiogenesis. Cancer J 6(Suppl 3):S245-S249.

Eto K, Puzon-McLaughlin W, Sheppard D, Sehara-Fujisawa A, Zhang XP, Takada Y. 2000. RGD-independent binding of integrin alpha9beta1 to the ADAM-12 and -15 disintegrin domains mediates cell-cell interaction. J Biol Chem 275:34922-34930.

Folkman J. 1990. What is the evidence that tumors are angiogenesis dependent? J Natl Cancer Inst 82:4-6.

Fritzsche FR, Jung M, Tolle A, Wild P, Hartmann A, Wassermann K, Rabien A, Lein M, Dietel M, Pilarsky C, Calvano D, Grutzmann R, Jung K, Kristiansen G. 2008. ADAM9 expression is a significant and independent prognostic marker of PSA relapse in prostate cancer. Eur Urol 54:1097-1108.

Glinsky GV, Krones-Herzig A, Glinskii AB. 2003. Malignancy-associated regions of transcriptional activation: Gene expression profiling identifies common chromosomal regions of a recurrent transcriptional activation in human prostate, breast, ovarian, and colon cancers. Neoplasia 5:218-228.

Gofuku J, Shiozaki H, Doki Y, Inoue M, Hirao M, Fukuchi N, Monden M. 1998. Characterization of soluble E-cadherin as a disease marker in gastric cancer patients. Br J Cancer 78:1095-1101.

Hajra KM, Ji X, Fearon ER. 1999. Extinction of E-cadherin expression in breast cancer via a dominant repression pathway acting on proximal promoter elements. Oncogene 18:7274-7279.

Ham C, Levkau B, Raines EW, Herren B. 2002. ADAM15 is an adherens junction molecule whose surface expression can be driven by VE-cadherin. Exp Cell Res 279:239-247.

Hanahan D, Weinberg RA. 2000. The hallmarks of cancer. Cell 100:57-70. Hart S, Fischer OM, Prenzel N, Zwick-Wallasch E, Schneider M, Hennighausen L, Ullrich A. 2005. GPCR-induced migration of breast carcinoma cells depends on both EGFR signal transactivation and EGFR-independent pathways. Biol Chem 386:845-855.

Hartmann D, de Strooper B, Serneels L, Craessaerts K, Herreman A, Annaert W, Umans L, Lubke T, Lena Illert A, von Figura K, Saftig P. 2002. The disintegrin/ metalloprotease ADAM 10 is essential for Notch signalling but not for alphasecretase activity in fibroblasts. Hum Mol Genet 11:2615-2624.

Horiuchi K, Weskamp G, Lum L, Hammes HP, Cai H, Brodie TA, Ludwig T, Chiusaroli R, Baron R, Preissner KT, Manova K, Blobel CP. 2003. Potential role for ADAM15 in pathological neovascularization in mice. Mol Cell Biol 23:5614-5624.

Karkkainen I, Karhu R, Huovila AP. 2000. Assignment of the ADAM15 gene to human chromosome band 1q21.3 by in situ hybridization. Cytogenet Cell Genet 88:206-207.

Kim S, Harris M, Varner JA. 2000. Regulation of integrin alpha vbeta 3mediated endothelial cell migration and angiogenesis by integrin alpha5beta1 and protein kinase A. J Biol Chem 275:33920-33928. 
Klessner JL, Desai BV, Amargo EV, Getsios S, Green KJ. 2009. EGFR and ADAMs cooperate to regulate shedding and endocytic trafficking of the desmosomal cadherin desmoglein 2. Mol Biol Cell 20:328-337.

Kratzschmar J, Lum L, Blobel CP. 1996. Metargidin, a membrane-anchored metalloprotease-disintegrin protein with an RGD integrin binding sequence. J Biol Chem 271:4593-4596.

Kuefer R, Hofer MD, Gschwend JE, Pienta KJ, Sanda MG, Chinnaiyan AM, Rubin MA, Day ML. 2003. The role of an $80 \mathrm{kDa}$ fragment of E-cadherin in the metastatic progression of prostate cancer. Clin Cancer Res 9:6447-6452.

Kuefer R, Day KC, Kleer CG, Sabel MS, Hofer MD, Varambally S, Zorn CS, Chinnaiyan AM, Rubin MA, Day ML. 2006. ADAM15 disintegrin is associated with aggressive prostate and breast cancer disease. Neoplasia 8:319-329.

Lapointe J, Li C, Higgins JP, van de Rijn M, Bair E, Montgomery K, Ferrari M, Egevad L, Rayford W, Bergerheim U, Ekman P, DeMarzo AM, Tibshirani R, Botstein D, Brown PO, Brooks JD, Pollack JR. 2004. Gene expression profiling identifies clinically relevant subtypes of prostate cancer. Proc Natl Acad Sci USA 101:811-816

Liu F, Wang JJ, You ZY, Zhang YD, Zhao Y. in press. Radiosensitivity of prostate cancer cells is enhanced by EGFR inhibitor C225. Urol Oncol.

Loechel F, Gilpin BJ, Engvall E, Albrechtsen R, Wewer UM. 1998. Human ADAM 12 (meltrin alpha) is an active metalloprotease. J Biol Chem 273:16993-16997.

Luo J, Duggan DJ, Chen Y, Sauvageot J, Ewing CM, Bittner ML, Trent JM, Isaacs WB. 2001. Human prostate cancer and benign prostatic hyperplasia: Molecular dissection by gene expression profiling. Cancer Res 61:4683-4688.

Magee JA, Araki T, Patil S, Ehrig T, True L, Humphrey PA, Catalona WJ, Watson MA, Milbrandt J. 2001. Expression profiling reveals hepsin overexpression in prostate cancer. Cancer Res 61:5692-5696.

Martin J, Eynstone LV, Davies M, Williams JD, Steadman R. 2002. The role of ADAM 15 in glomerular mesangial cell migration. J Biol Chem 277:3368333689.

McCrea PD, Gumbiner BM. 1991. Purification of a 92-kDa cytoplasmic protein tightly associated with the cell-cell adhesion molecule E-cadherin (uvomorulin). Characterization and extractability of the protein complex from the cell cytostructure. J Biol Chem 266:4514-4520.

Miller JR, Moon RT. 1997. Analysis of the signaling activities of localization mutants of beta-catenin during axis specification in Xenopus. J Cell Biol 139:229-243.

Moiseeva EP. 2001. Adhesion receptors of vascular smooth muscle cells and their functions. Cardiovasc Res 52:372-386.

Murant SJ, Rolley N, Phillips SM, Stower M, Maitland NJ. 2000. Allelic imbalance within the E-cadherin gene is an infrequent event in prostate carcinogenesis. Genes Chromosomes Cancer 27:104-109.

Murphy G. 2008. The ADAMs: Signalling scissors in the tumour microenvironment. Nat Rev Cancer 8:929-941.

Nagafuchi A, Takeichi M. 1989. Transmembrane control of cadherinmediated cell adhesion: A $94 \mathrm{kDa}$ protein functionally associated with a specific region of the cytoplasmic domain of E-cadherin. Cell Regul 1:37-44.

Najy AJ, Day KC, Day ML. 2008a. ADAM15 supports prostate cancer metastasis by modulating tumor cell-endothelial cell interaction. Cancer Res 68:1092-1099.

Najy AJ, Day KC, Day ML. 2008b. The ectodomain shedding of E-cadherin by ADAM15 supports ErbB receptor activation. J Biol Chem 283:18393-183401.

Nath D, Slocombe PM, Stephens PE, Warn A, Hutchinson GR, Yamada KM, Docherty AJ, Murphy G. 1999. Interaction of metargidin (ADAM-15) with alphavbeta3 and alpha5beta1 integrins on different haemopoietic cells. J Cell Sci 112(Pt 4):579-587.

Nieman MT, Prudoff RS, Johnson KR, Wheelock MJ. 1999. N-cadherin promotes motility in human breast cancer cells regardless of their E-cadherin expression. J Cell Biol 147:631-644.
Ohtsu H, Dempsey PJ, Eguchi S. 2006. ADAMs as mediators of EGF receptor transactivation by G protein-coupled receptors. Am J Physiol Cell Physiol 291:C1-C10.

Peduto L, Reuter VE, Shaffer DR, Scher HI, Blobel CP. 2005. Critical function for ADAM9 in mouse prostate cancer. Cancer Res 65:9312-9319.

Schafer S, Koch PJ, Franke WW. 1994. Identification of the ubiquitous human desmoglein, Dsg2, and the expression catalogue of the desmoglein subfamily of desmosomal cadherins. Exp Cell Res 211:391-399.

Schafer B, Marg B, Gschwind A, Ullrich A. 2004. Distinct ADAM metalloproteinases regulate $\mathrm{G}$ protein-coupled receptor-induced cell proliferation and survival. J Biol Chem 279:47929-47938.

Shi Y, Brands FH, Chatterjee S, Feng AC, Groshen S, Schewe J, Lieskovsky G, Cote RJ. 2001. Her-2/neu expression in prostate cancer: High level of expression associated with exposure to hormone therapy and androgen independent disease. J Urol 166:1514-1519.

Shi XB, Ma AH, Tepper CG, Xia L, Gregg JP, Gandour-Edwards R, Mack PC, Kung HJ, deVere White RW. 2004. Molecular alterations associated with LNCaP cell progression to androgen independence. Prostate 60:257271.

Shiina H, Breault JE, Basset WW, Enokida H, Urakami S, Li LC, Okino ST, Deguchi M, Kaneuchi M, Terashima M, Yoneda T, Shigeno K, Carroll PR, Igawa M, Dahiya R. 2005. Functional Loss of the gamma-catenin gene through epigenetic and genetic pathways in human prostate cancer. Cancer Res 65:2130-2138.

Signoretti S, Montironi R, Manola J, Altimari A, Tam C, Bubley G, Balk S, Thomas G, Kaplan I, Hlatky L, Hahnfeldt P, Kantoff P, Loda M. 2000. Her-2neu expression and progression toward androgen independence in human prostate cancer. J Natl Cancer Inst 92:1918-1925.

Smith KM, Gaultier A, Cousin H, Alfandari D, White JM, DeSimone DW. 2002. The cysteine-rich domain regulates ADAM protease function in vivo. J Cell Biol 159:893-902.

Suyama K, Shapiro I, Guttman M, Hazan RB. 2002. A signaling pathway leading to metastasis is controlled by $\mathrm{N}$-cadherin and the FGF receptor. Cancer Cell 2:301-314.

Tomlins SA, Mehra R, Rhodes DR, Cao X, Wang L, Dhanasekaran SM, Kalyana-Sundaram S, Wei JT, Rubin MA, Pienta KJ, Shah RB, Chinnaiyan AM. 2007. Integrative molecular concept modeling of prostate cancer progression. Nat Genet 39:41-51.

Trochon-Joseph V, Martel-Renoir D, Mir LM, Thomaidis A, Opolon P, Connault E, Li H, Grenet C, Fauvel-Lafeve F, Soria J, Legrand C, Soria C, Perricaudet M, Lu H. 2004. Evidence of antiangiogenic and antimetastatic activities of the recombinant disintegrin domain of metargidin. Cancer Res 64:2062-2069.

Vanaja DK, Cheville JC, Iturria SJ, Young CY. 2003. Transcriptional silencing of zinc finger protein 185 identified by expression profiling is associated with prostate cancer progression. Cancer Res 63:3877-3882.

Varambally S, Yu J, Laxman B, Rhodes DR, Mehra R, Tomlins SA, Shah RB, Chandran U, Monzon FA, Becich MJ, Wei JT, Pienta KJ, Ghosh D, Rubin MA, Chinnaiyan AM. 2005. Integrative genomic and proteomic analysis of prostate cancer reveals signatures of metastatic progression. Cancer Cell 8:393-406.

Visakorpi T, Kallioniemi OP, Koivula T, Harvey J, Isola J. 1992. Expression of epidermal growth factor receptor and ERBB2 (HER-2/Neu) oncoprotein in prostatic carcinomas. Mod Pathol 5:643-648.

Wheelock MJ, Buck CA, Bechtol KB, Damsky CH. 1987. Soluble 80-kd fragment of cell-CAM 120/80 disrupts cell-cell adhesion. J Cell Biochem $34: 187-202$

Witters L, Scherle P, Friedman S, Fridman J, Caulder E, Newton R, Lipton A. 2008. Synergistic inhibition with a dual epidermal growth factor receptor/ HER-2/neu tyrosine kinase inhibitor and a disintegrin and metalloprotease inhibitor. Cancer Res 68:7083-7089. 
Wolfsberg TG, Bazan JF, Blobel CP, Myles DG, Primakoff P, White JM. 1993. The precursor region of a protein active in sperm-egg fusion contains a metalloprotease and a disintegrin domain: Structural, functional, and evolutionary implications. Proc Natl Acad Sci USA 90:10783-10787.

Wolfsberg TG, Primakoff P, Myles DG, White JM. 1995. ADAM, a novel family of membrane proteins containing A Disintegrin And Metalloprotease domain: Multipotential functions in cell-cell and cell-matrix interactions. J Cell Biol 131:275-278.

Yu YP, Landsittel D, Jing L, Nelson J, Ren B, Liu L, McDonald C, Thomas R, Dhir R, Finkelstein S, Michalopoulos G, Becich M, Luo JH. 2004. Gene expression alterations in prostate cancer predicting tumor aggression and preceding development of malignancy. J Clin Oncol 22:2790-2799.
Zhang XP, Kamata T, Yokoyama K, Puzon-McLaughlin W, Takada Y. 1998. Specific interaction of the recombinant disintegrin-like domain of MDC-15 (metargidin, ADAM-15) with integrin alphavbeta3. J Biol Chem 273:73457350.

Zhang L, Shi J, Feng J, Klocker H, Lee C, Zhang J. 2004. Type IV collagenase (matrix metalloproteinase-2 and -9) in prostate cancer. Prostate Cancer Prostatic Dis 7:327-332.

Zhao J, Chen H, Peschon JJ, Shi W, Zhang Y, Frank SJ, Warburton D. 2001. Pulmonary hypoplasia in mice lacking tumor necrosis factor-alpha converting enzyme indicates an indispensable role for cell surface protein shedding during embryonic lung branching morphogenesis. Dev Biol 232:204-218. 